\title{
Mink with Divergent Activity Levels have Divergent Reproductive Strategies
}

\author{
Rebecca K. Meagher*, Allison Bechard*† \& Georgia J. Mason* \\ * Animal \& Poultry Science, University of Guelph, Guelph, ON, Canada \\ $\uparrow$ Department of Psychology, University of Florida, Gainesville, FL, USA
}

\section{Correspondence}

Rebecca K. Meagher, Animal \& Poultry Science, University of Guelph, 50 Stone Road East, Building \#70, Guelph, ON N1G 2W1, Canada.

E-mail: rmeagher@uoguelph.ca

Received: January 20, 2012

Initial acceptance: February 14, 2012

Final acceptance: March 23, 2012

(S. Foster)

doi: 10.1111/j.1439-0310.2012.02044.x

\begin{abstract}
Stable individual differences in activity levels within populations have been linked to differences in reproductive rate or parental care in several species, including American mink (Neovison vison). Fur-farmed mink are good models for studying such effects because they yield large sample sizes and readily allow investigations into maternal behaviour, reproductive success, offspring performance and the relationships between these factors. On farms, very inactive individuals generally have smaller litters, and this held true in our study populations. We tested two competing hypotheses to explain this: (1) inactive individuals are failing to cope with a challenging environment and experiencing chronic stress and/or depression-like 'apathy'; this predicts female-skewed litters, poorer maternal care, higher infant mortality and poorer infant growth and (2) inactive individuals do not have reduced fitness but instead employ an alternative adaptive reproductive strategy, trading off offspring quantity for quality; this predicts enhanced maternal care, reduced infant mortality and enhanced infant growth. Inactive females' kits, especially their sons, grew faster than active females', even after statistically controlling for litter size; and by $21 \mathrm{~d}$, inactive and active dams' litters no longer differed in total biomass, despite the former's smaller litter sizes. In kit retrieval tests, inactive females were faster than active dams to reach their sons (as well as more likely to contact their sons than their daughters: a bias towards male kits not evident in the active dams). Furthermore, kit growth rates and dam latencies to touch them co-varied, suggesting the existence of consistent differences in maternal style across inactive and active dams. Hypothesis 2 was thus supported: inactive females favour offspring quality over quantity, investing more resources in fewer kits, particularly males. This potentially boosts their sons' adult fitness. More broadly for laboratory-based studies, possible 'captivity effects' on the fitness correlates of activity and other personality traits are discussed.
\end{abstract}

\section{Introduction}

Within populations of a given species, there is often a great deal of stable inter-individual variation in activity levels, and this variation may correlate with life history strategies. Fur-farmed American mink
(Neovison vison) illustrate this potentially extreme variation particularly well. During the season (winter) and time of day (morning, before the daily meal; Mason 1993; Hansen \& Møller 2008) when mink are most active, some individuals are active for $80 \%$ or more of the time (Bildsøe et al. 1991; Svendsen 
et al. 2007a), while others spend $90 \%$ of this period recumbent in their nest-boxes (Meagher 8 Mason 2008). These individual differences predict 24 -h time budgets, because mink that are more or less active at these times are correspondingly more or less active overall (Mason 1992; Svendsen et al. 2007b). In this species, such differences in activity levels also correlate with reproductive differences in terms of annual litter size, with the most highly active females producing the largest litters (Mason 1992; Jeppesen et al. 2004; Meagher et al. 2010). Our aim here was to investigate why this is the case.

For captive animals on farms and in zoos, such differential activity is often studied and interpreted from an animal welfare perspective. Their inactivity may be hypothesized to reflect hiding, resulting from chronic fear (e.g. Carlstead et al. 1993; Rochlitz et al. 1998). Inspired by laboratory rodent and human clinical findings that chronic stress can induce 'apathetic' depression-like states (cf. Willner 1997; Anisman \& Matheson 2005), very inactive subjects may instead be hypothesized to be apathetic (e.g. Cronin 1985; Wielebnowski et al. 2002), 'lethargic' (e.g. Zeller 1991; Wemelsfelder et al. 2009) or 'depressed' (Carlstead 1996; Carlstead et al. 1999). Extreme inactivity can thus be hypothesized to reflect a failure to cope with a challenging environment. Consistent with this view, the stereotypic behaviours common in highly active captive individuals often seemed empirically linked with lower stress levels than those of more inactive conspecifics in the same conditions, suggesting that the latter do have reduced abilities to cope with sub-optimal housing (Mason \& Latham 2004). There is some behavioural and endocrine evidence that this might be the case for farmed mink, although it is not consistent across studies. Thus, some studies report that, compared to active mink, inactive mink are more likely to be timid (Hansen \& Jeppesen 2006) and have higher baseline cortisol levels (Bildsøe et al. 1991), suggesting greater chronic stress. However, other studies report no significant relationships between inactivity and temperament (Korhonen et al. 2002; Svendsen et al. 2007a) or even reduced cortisol levels in inactive animals (Svendsen et al. 2007a; Meagher et al. in press), perhaps reflecting that corticosteroid levels can be elevated by physical activity per se (e.g. Girard \& Garland 2002).

The smaller litter sizes of inactive mink could be viewed as further evidence that these individuals have reduced abilities to cope, because chronic stress decreases fertility, including average litter sizes, across multiple species (Hemsworth 2003; Wingfield
\& Sapolsky 2003). Stronger evidence, however, would also include the following four reproductive changes, not yet compared across the behavioural phenotypes of mink. First, the offspring ('kits') of inactive females should show impaired growth (e.g. as occurs in mink kits whose dams are experimentally stressed (Dobson et al. 2008) and sometimes in the children of depressed mothers (Stewart 2007). Second, inactive females should show increased offspring mortality rates (e.g. as occurs in the piglets of fearful sows: Janczak et al. 2003). Third, relatedly, they should show reduced maternal care (e.g. as occurs in stressed captive gorillas: Bahr et al. 1998), including decreased maternal responsiveness (e.g. as occurs in depressed human mothers: Stewart 2007). Fourth and finally, assuming that maternal investment affects male offspring reproductive success in adulthood (see, for example, Wells 2003), which is more variable than female reproductive success in promiscuous species such as the mink (Faust $\delta$ Thompson 2000), and assuming that other factors (e.g. sex-specific philopatry, absent in mink) are not at work, then poor quality mothers should produce female-biased litters (Trivers \& Willard 1973; Faust \& Thompson 2000). In other species where such assumptions hold, stressed dams do produce more female than male offspring (e.g. silver foxes, Vulpes vulpes: Bakken 1995, 1998). These reproductive predictions of the 'failure to cope' hypothesis were our focus here.

Behavioural ecology research on personality and behavioural syndromes offers an alternative, competing perspective on inactivity levels and their link with small litter sizes: that differences in activity reflect adaptive personality traits that are not directly related to stress or the coping abilities of the individual. Personality refers to a set of behavioural characteristics in an individual that are consistent over time and across contexts (Gosling 2001; Réale et al. 2007). Inter-correlated personality traits are sometimes termed 'behavioural syndromes' (Réale et al. 2007); for example, activity, exploratory behaviour and boldness are frequently co-associated in a single behavioural syndrome (Sih et al. 2004). Boldness has also been linked with increased aggression (Koolhaas et al. 1999) and tendencies to form routines (Verbeek et al. 1994), and low exploration with tendencies to show immobility and little aggression under stress (Koolhaas et al. 1999). Minks' individual differences in activity could well be considered an aspect of personality, and perhaps part of a broader behavioural syndrome. These differences are also heritable (e.g. Hansen 1993) and consistent 
across long time periods (Mason 1993) and different housing conditions (M. Díez-León \& G. Mason, personal communication). The phenotypes also differ in other behavioural traits. Inactivity is negatively correlated with stereotypic behaviours such as repetitive pacing (Bildsøe et al. 1991; Svendsen et al. 2007a), and this in turn correlates with increased routineproneness (Dallaire et al. 2011); inactive mink are thus less prone to behavioural routines.

Multiple evolutionary explanations have been proposed for the existence of alternative personalities or behavioural syndromes within populations. Sometimes they may reflect variation in fitness, with relatively unfit (e.g. subordinate) individuals 'making the best of a bad job' via timid, non-aggressive phenotypes (Dall et al. 2004). In other cases, however, they represent alternative adaptive strategies with similar fitness, perhaps differentially favoured according to current circumstances [e.g. trait frequencies within the population (Réale et al. 2007) or food abundance (Boon et al. 2007)]. In such cases, the different syndromes may diverge in tradeoffs between the various life history traits that affect fitness. To illustrate, activity/boldness has often been linked to trade-offs between fecundity and mortality, with active, bold animals showing greater reproductive rates but shorter lifespans because of elevated risk-taking and faster 'paces of life' involving less investment in long-term survival (e.g. Careau et al. $2008,2010)$. Such hypotheses are supported by evolutionary modelling (Wolf et al. 2007), as well as some data (e.g. Biro \& Stamps 2008). These bold, active, rapidly reproducing individuals are further hypothesized to allocate less maternal care to their individual young (Réale et al. 2010) in trade-offs resembling those seen across ' $\mathrm{R}-$ ' and 'K-selected' species (Jeschke \& Kokko 2009). In humans, personality is indeed linked to such trade-offs between offspring quantity and quality: women scoring lower in the trait 'neuroticism' raise fewer but larger offspring (Alvergne et al. 2010). In non-human animals, however, although certain aspects of maternal behaviour are known to co-vary with some personality traits (e.g. Hollander et al. 2008), these specific adaptive reproductive trade-offs have not yet been shown to vary across individuals with divergent behavioural syndromes. Together, these data and hypotheses suggest that in mink, active and inactive phenotypes could have evolved different reproductive strategies. More specifically, inactive mothers' decreased litter sizes might be part of a trade-off between offspring number and quality, with these mothers showing more maternal care, and their kits, enhanced growth and reduced mortality. There is some preliminary evidence for this hypothesis: kits raised by inactive/non-stereotypic foster-mothers grow faster than do those fostered to active/stereotypic dams (Mason et al. 1995).

We used farmed mink as a model to test these two competing hypotheses from, respectively, applied animal welfare and human psychology research, and fundamental behavioural ecology research on personality or behavioural syndromes, to investigate why very inactive captive mink often have small litters. The testable predictions of the two hypotheses are summarized in Table 1. Farmed mink yield unusually large sample sizes while also allowing direct observation of maternal behaviour in a manner not feasible in the wild or even in laboratory conditions. This allowed us to determine, for the first time, how all these variables interrelate in a single system.

\section{Methods}

\section{Subjects}

A total of 549 females entering their second or third breeding season were observed across three farms in south-western Ontario. At Farm 1, we observed mink of two colour-types (lines bred for fur colours): 149 Blacks and 144 Pastels. These colour-types differ in temperament and average activity level, with Blacks typically being more active and more 'nervous' (European Commission 2001; Meagher et al. 2011). The other farms had only one colour-type each: we sampled 143 Blacks at Farm 2, and 113 Pastels at Farm 3. Mink were individually housed in wire-mesh cages with a wooden nest-box (a cube with sides $18 \mathrm{~cm}$ long). Nesting material was provided

Table 1: Summary of predictions made by the alternative hypotheses

\begin{tabular}{lll}
\hline $\begin{array}{l}\text { Prediction for inactive dams } \\
\text { (compared to active dams) }\end{array}$ & $\begin{array}{l}\text { 'Failure to cope' } \\
\text { hypothesis }\end{array}$ & $\begin{array}{l}\text { 'Alternative life } \\
\text { history strategies' } \\
\text { hypothesis }\end{array}$ \\
\hline $\begin{array}{l}\text { Maternal responsiveness } \\
\text { to offspring }\end{array}$ & Reduced & Increased \\
Infant growth rates & Reduced & Increased \\
Infant mortality rates & Increased & Decreased \\
$\begin{array}{l}\text { Sex ratio of litter } \\
\text { Tested elsewhere (Meagher } \\
\text { et al. in press): cortisol }\end{array}$ & $\begin{array}{l}\text { Female-biased } \\
\text { Increased }\end{array}$ & NSD \\
$\begin{array}{l}\text { Not tested yet: lifespan, if } \\
\text { allowed to live into }\end{array}$ & Decreased & \\
senescence & & Increased \\
\hline
\end{tabular}

NSD, no significant difference. 
beginning shortly before any mink gave birth; at Farm 1, wheat straw was provided, while Farms 2 and 3 used aspen shavings instead. Exact cage-sizes varied but met Canadian Codes (being $61 \mathrm{~cm} \times$ $19 \mathrm{~cm} \times 46 \mathrm{~cm}$ or greater). Mink had access to water ad libitum and were fed once daily. The University of Guelph's Animal Care Committee approved the research.

\section{Behaviour in the Pre-Mating Period and Maternal Characteristics}

Subjects were screened for inactivity in February. Live behavioural scanning was conducted daily from 09:00 until feeding began (c.13:00-13:30), for nine or $10 \mathrm{~d}$. Live scanning has been validated by correlation with video data (Bildsøe et al. 1990; Svendsen et al. 2007b). Analyses were based on percentage of scans spent inactive (lying down/out of sight in nest-box), and stereotypic behaviour (defined as a sequence repeated at least three times consecutively) was recorded separately from 'normal' activity.

Inactive mink tend to be fatter (Jeppesen et al. 2004; Hansen \& Møller 2008), which could have a confounding effect on offspring sex ratios (Cameron 2004) and infant growth. To control for this, farmers scored animals for body condition on a 5-point scale, from very thin to very heavy, where three represented the 'ideal' (cf. Hynes et al. 2008). To attain acceptable reliability (intra-observer reliability of kappa >0.4), scores were pooled into three simpler categories: thin, normal (scores 2.5-3.5) and overweight (Meagher et al. in press provides statistical details).

\section{Litter Characteristics and Kit Performance}

Kits were counted, sexed and weighed on post-natal days (PND) 1 and 21: a period when kits depend fully on mothers for food (Dunstone 1993; Mason 1994) and thermoregulation (Harjunpaa \& Rouvinen-Watt 2004). Weights were averaged for each litter, split by sex. Sexual dimorphism is clearer at PND 21 than PND 1, making sexing more reliable at this age (data at PND 21 revealed that $4.5 \%$ of litters had a kit mis-sexed at PND 1); sex ratio at $21 \mathrm{~d}$ is thus taken as our measure of sex ratio. Growth rates were calculated as differences in average kit weight between PND 1 and 21 , divided by $20 \mathrm{~d}$, for each sex. Removing the litters with ambiguous sexing on PND 1 did not affect growth rate results, and thus they were included in the analyses presented here. Kit mortality distinguished between deaths during the first $24 \mathrm{~h}$ (including stillbirths) and mortality after that time. Farmers cross-fostered some kits, or rescued kits that had been chilled, according to their standard farm practices. However, litters in which this occurred were excluded from the litter size and sex ratio analyses.

\section{Maternal Behaviour}

Three characteristics of nest-building were scored: the presence/absence of nest material, the shape into which that material was formed and the amount of fur incorporated. In rabbits, where this is best studied, using fur in nest-building is a maternal behaviour controlled by progesterone and prolactin (Zarrow et al. 1961) and improves offspring growth and survival (Marai \& Rashwan 2003). Wild mustelids similarly line nests with fur (King \& Powell 2007), as do domestic ferrets (Roberts 1977), although the mechanisms and effects on their offspring are unknown. Fur was scored on a threepoint scale: (0) no fur; (1) a few clumps; (2) fur throughout nest. The presence of nesting material (e.g. straw) influences mink kit growth and survival (Malmkvist \& Palme 2008). Furthermore, the shape of the structure created affects offspring performance in other species (Andersen et al. 2005; Deacon 2006; Pedersen et al. 2006). Nest shape was therefore rated from 1 to 7 , where one signified that all nesting material was ejected, with none present around kits, and seven signified a fully enclosed nest (details in Table 2; cf. Malmkvist \& Palme 2008). The maximum possible score at Farms 2 and 3 was only 5 because of the lack of straw. Nests were scored every second day from late April until a score was obtained for each mink $1-2 \mathrm{~d}$ before giving birth and $1-2 \mathrm{~d}$ after.

Kit retrieval tests (Malmkvist \& Houbak 2000) were used to assess maternal responsiveness in a subset of females selected using February inactivity levels; 25 of the most inactive and 25 of the least

Table 2: Nest shape scale

\begin{tabular}{ll}
\hline Score & Description \\
\hline 1 & No nesting material \\
2 & Some nesting material; flat, unstructured \\
3 & All nesting material remaining; flat, unstructured \\
4 & Saucer-shaped indentation \\
5 & Round hole with sides higher than the dam when lying down \\
6 & Round hole with partial 'ceiling' \\
7 & At least 75\% of nest covered by 'ceiling' \\
\hline
\end{tabular}


inactive females from each farm and colour-type were included (excluding females with fewer than four kits, to reduce potentially confounding effects of litter size): 200 in total. Tests occurred in the mornings of PND 5. One kit per litter was selected at random, and its sex noted; it was then placed in the cage centre, head facing the nest-box. The times taken for the mother to touch it and return it to the nest-box were recorded (for a maximum of $180 \mathrm{~s}$ to prevent kits becoming chilled).

\section{Statistical Analysis}

Analyses were conducted in JMP 8 or SAS 9 (SAS Institute Inc., Cary, NC, USA). Females that did not produce litters were excluded from all analyses. Relationships between inactivity and temperament, body condition, litter size, sex ratio and growth rates were analysed using general linear models (GLMs), controlling for farm, colour-type and, where appropriate, litter size. Relationships of interest between dependent variables were analysed similarly. Farm was a random effect, and restricted maximum likelihood (REML) methods of estimation were employed as recommended for mixed models (Searle et al. 1992). Exceptions were sex ratio models, which would only run if farm was treated as fixed, and models for kit growth include both sexes, where farm and colour-type were combined into a single fixed effect labelled 'group' to allow nesting of individual within group. Effects of farm, colour-type and litter size are not presented here unless interacting with variables of interest. Because nest scores were ordinal, inactivity was used as the dependent variable to allow use of GLMs. Tests were two-tailed. Normality and homogeneity of variance were assessed by inspection of residuals (Grafen $\&$ Hails 2002); Bartlett's test for equal variances was used for categorical effects. Data were transformed where needed to meet the assumptions of parametric tests (e.g. inactivity was logit-transformed in nest score analyses, while latencies to touch and retrieve kits were log-transformed). Where the assumptions could not be met, non-parametric generalized linear mixed models were used (e.g. for relationships between kit mortality and dam inactivity; nest scores; and retrieval times). Two extreme outliers (probably measurement errors) were removed from male growth analyses.

Kit retrieval tests showed ceiling effects because some mothers did not retrieve within the allotted time. Survival analyses were considered, but their assumptions were violated: the active/inactive groups' survival curves crossed (Kleinbaum \& Klein 2005). Probabilities of failure to respond were therefore analysed separately using chi-squared tests, and non-retrieving mothers were excluded from further analyses of latencies.

\section{Results}

\section{Dam Behaviour and Litter Characteristics}

Subjects varied greatly in activity; the least active spent up to $98 \%$ of the observation period inactive, while the most active were never recorded inactive. As expected, body condition and inactivity positively co-varied $\left(F_{2,486}=28.0, \mathrm{p}<0.0001\right.$; see Table 3 for more details). Also as expected, high inactivity predicted small birth litter sizes $\left(\mathrm{N}=343, F_{1,178}=4.49\right.$, $\mathrm{p}=0.035$, regression coefficient: -0.0124$)$. For sex ratio effects, there was a non-significant trend for an interaction between colour-type and inactivity $\left(F_{1,315}=2.90, \mathrm{p}=0.090\right)$. When the analysis was split by colour, a non-significant trend for a negative correlation between sex ratio (proportion of litter that is male) and inactivity existed in Pastels only $\left(F_{1,143}=3.19, \mathrm{p}=0.076\right)$.

\section{Kit Weight, Growth and Mortality Rates}

Details of kit weight and growth rate results are presented in Table 4. Inactivity did not have a significant main effect on individual kit weight on PND 1. For kit growth rates, dam inactivity and kit sex interacted $\left(F_{1,800}=6.68, \mathrm{p}=0.010\right)$. Split by kit sex, inactivity significantly predicted enhanced growth in both males and females, but for males, this interacted with litter size (see Table 4), and the slope of the inactivity main effect was steeper for males than for females (Fig. 1). These results control for litter size and thus are not simply by-products of inactive dams having fewer kits. Controlling for dam body condition did not eliminate this effect (males: $F_{1,381}=42.2, \mathrm{p}<0.0001$; females: $F_{1,382}=16.0, \mathrm{p}<$ $0.0001)$. Inactivity tended to predict relatively small total litter biomasses on PND $1 \quad\left(F_{1,293}=3.28\right.$,

Table 3: Distribution of body condition among animals at extremes for inactivity (defined by the first and third quartiles)

\begin{tabular}{lccc}
\hline Body condition & N & Active (\%) & Inactive (\%) \\
\hline Fat & 241 & 6 & 14 \\
Normal & & 88 & 84 \\
Thin & 6 & 2 \\
\hline
\end{tabular}


Table 4: Dam inactivity as a predictor of kit weight and growth

\begin{tabular}{|c|c|c|c|c|}
\hline \multirow[b]{2}{*}{ Predictor DV } & \multicolumn{2}{|l|}{ Male kits } & \multicolumn{2}{|l|}{ Female kits } \\
\hline & Inactivity main effect & Relevant interactions & Inactivity main effect & Relevant interactions \\
\hline Weight PND 1 & $p>0.10$ & $\begin{array}{l}\text { Inactivity*colour: } \\
F_{1,400}=3.70, p=0.055 \\
\text { Blacks: }+ \text { ve } \\
F_{1,223}=4.21, p=0.041 \\
\text { Pastels: } p>0.10\end{array}$ & $p>0.10$ & $\begin{array}{l}\text { Inactivity*litter size }{ }^{\star} \text { colour: } \\
F_{1,419}=3.28, p=0.071 \\
\text { Blacks: } p>0.10 \\
\text { Pastels: Inactivity*litter size: } \\
F_{1,191}=3.12, p=0.079\end{array}$ \\
\hline Growth from & $+\mathrm{ve}$ & Inactivity*litter size: & +ve & None \\
\hline $\begin{array}{l}\text { PND } 1 \text { to } \\
\text { PND } 21\end{array}$ & $\begin{array}{l}F_{1,397}=42.39 \\
p<0.0001\end{array}$ & $\begin{array}{l}F_{1,396}=4.91, p=0.027 \\
\text { (stronger in small litters) }\end{array}$ & $\begin{array}{c}F_{1,405}=22.57 \\
p<0.0001\end{array}$ & \\
\hline
\end{tabular}

DV, dependent variable; PND, post-natal day.

Interactions are presented if they had $p<0.10$. Details of relevant interactions are given in italics. In the case of interactions with colour-type, the statistics presented in italics are from analyses split by colour-type.

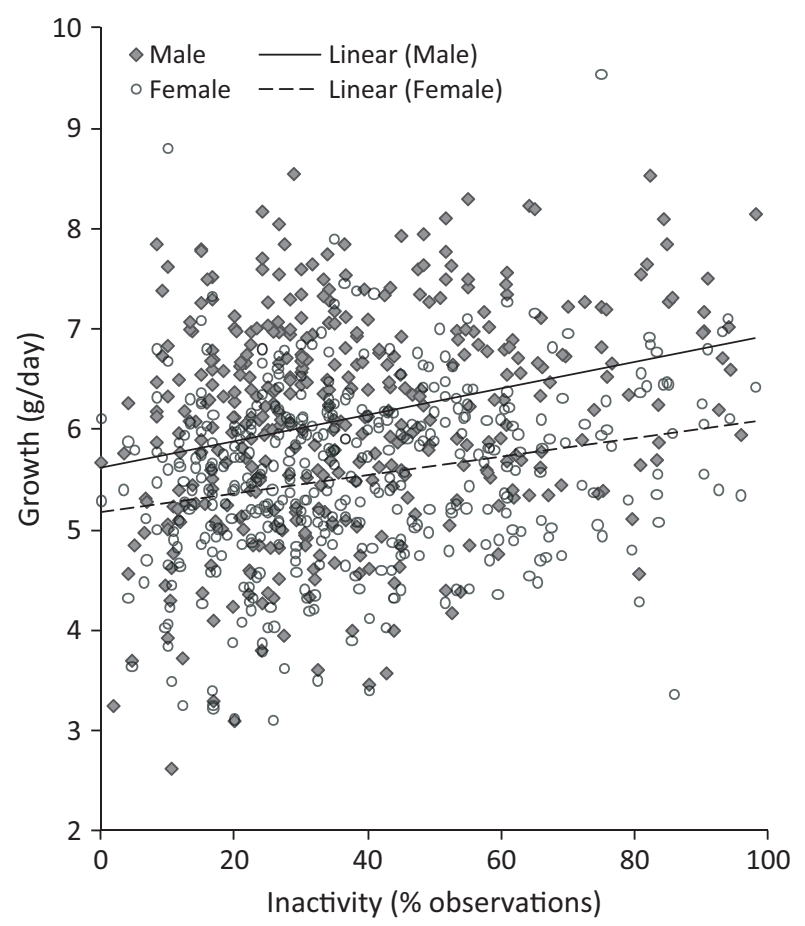

Fig. 1: Kit growth vs. maternal inactivity. $\mathrm{N}=403$ litters for males, 411 litters for females. Growth rates were calculated separately for each sex within the litter, and a line of best fit for each sex is shown.

$\mathrm{p}=0.071)$, but because of these dams' faster kit growth, this effect disappeared by PND 21 ( $\mathrm{p}>$ $0.10)$. Inactivity levels did not predict kit mortality at either stage (both $\mathrm{p}>0.10$ ).

\section{Maternal Behaviour}

In kit retrieval tests, response failures did not differ between active and inactive groups (Blacks: $11 \%$ of inactive vs. $14 \%$ of active dams, $\chi_{1}^{2}=0.167, \mathrm{p}=$

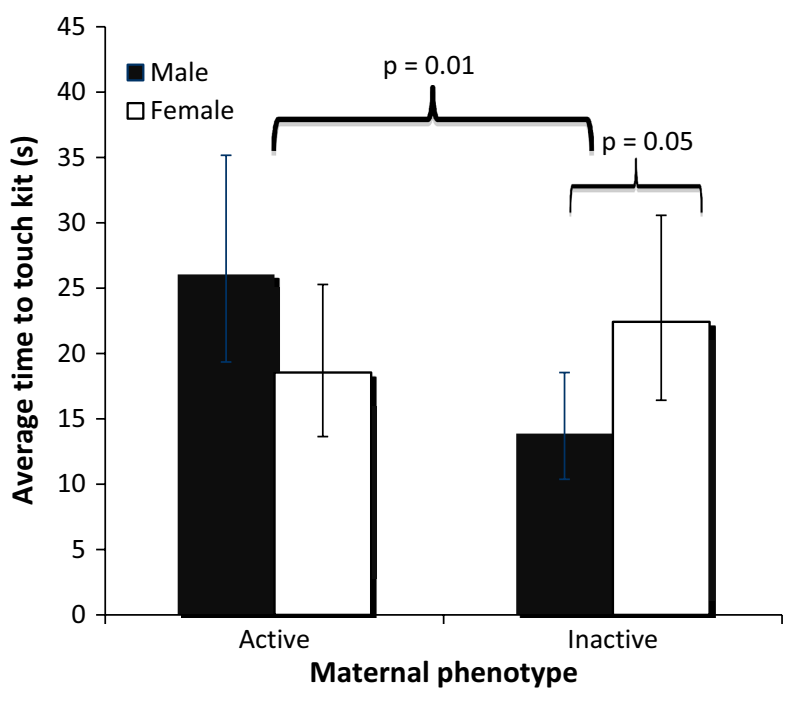

Fig. 2: Latency to touch kits vs. inactivity. Values are back-transformed least squares means. Error bars indicate confidence intervals. Statistically significant contrasts $(p<0.05)$ are labelled. $N=161$.

0.682; Pastels: $14 \%$ of inactive vs. $10 \%$ of active dams, $\left.\chi_{1}^{2}=0.308, \quad p=0.579\right)$. However, inactive mothers were more likely to touch their sons than their daughters $(94.3 \%$ vs. $79.5 \%$ touched, respectively, Fisher's exact $\mathrm{p}=0.033, \mathrm{~N}=97$ ) - an effect that was non-significant in active mothers $(93.6 \%$ for sons vs. $81.4 \%$ for daughters; Fisher's exact $\mathrm{p}=0.109, \mathrm{~N}=90)$. Response failures did not predict kit mortality or growth $(\mathrm{p}>0.10)$.

For mothers that did respond, there was no effect of inactivity or kit sex on total retrieval time (both $\mathrm{p}>0.10)$. However, for latency to first touch, inactivity and kit sex interacted $\left(F_{1,153}=5.29, \mathrm{p}=\right.$ $0.023)$, with males being touched faster by inactive than active dams (Fig. 2). Litter size was unrelated 
to latencies to touch or retrieve kits (both $\mathrm{p}>0.05$ ). Again, neither latency to touch nor to retrieve predicted kit mortality (both $\mathrm{p}>0.10$ ). However, latency to touch predicted kit growth rates, averaged across sexes (Fig. 3; $\left.F_{1,159}=7.96, \quad \mathrm{p}=0.005\right)$. Latency to retrieve also predicted kit growth in Pastels $\left(F_{1,67}=5.63, \mathrm{p}=0.021\right)$ - shorter latencies correlating with increased growth.

The presence of nest fur before parturition covaried with inactivity, higher inactivity being associated with more fur $\left(F_{2,389}=3.47, \mathrm{p}=0.033\right)$, although such effects vanished post-parturition. No dams ejected all of their nesting material from nestboxes, so no analyses were needed for simple presence vs. absence of nesting material. However, nest shape scores before the day of parturition correlated negatively with inactivity, an effect that was the strongest among Blacks (colour*shape $F_{7,446}=2.97$, $\mathrm{p}=0.005)$. Nest shape post partum was, however, unrelated to dam activity levels $\left(F_{6,426}=0.81\right.$, $\mathrm{p}=0.558)$.

\section{Discussion}

We tested two potential explanations for the smaller annual litters of highly inactive mink: the 'failure to cope' and 'alternative strategies' hypotheses. Only one finding was potentially consistent with the stress hypothesis: inactive females had lower nest shape scores before parturition. However, our use of nest quality to indicate maternal care was rather exploratory, and like other authors (Møller 1990), we

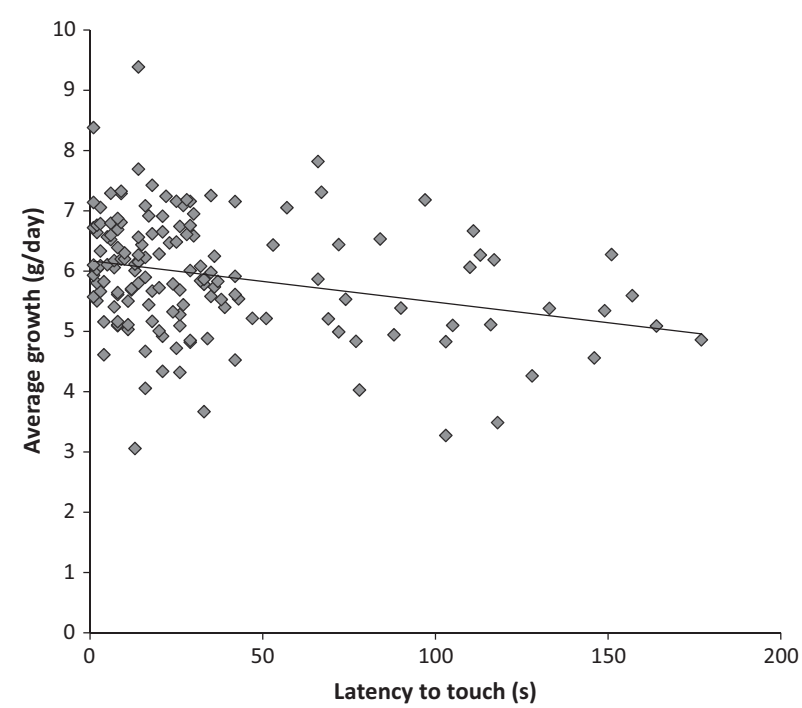

Fig. 3: Kit growth vs. latency to touch in retrieval tests. $N=168$. Growth values are averaged across male and female kits. found no evidence that this score is biologically relevant for farmed mink: it did not predict kit mortality or growth. Furthermore, inactive dams did not have elevated cortisol nor elevated fear (Meagher et al. in press); thus, stress could not explain their reduced litter sizes.

The 'alternative strategies' hypothesis was far more convincingly supported. According to kit growth rate and retrieval data, inactive females invested more resources per kit. Both effects were significant even after controlling for litter size, thus increased growth in kits with inactive mothers did not just reflect trade-offs between litter size and body size of individual offspring because of finite resources (e.g. milk; Sikes \& Ylönen 1998); nor were retrieval results mere side effects of small litters resulting in fewer kits in the nest-box competing for the mother's attention (Clausen et al. 2008). Furthermore, dam inactivity levels predicted faster kits' growth rates even when their greater body condition, likely associated with larger energy reserves to support lactation, was statistically controlled for. Combined with our finding that shorter latencies to retrieve were statistically related to faster kit growth, this strongly suggests that inactive dams' enhanced maternal responsiveness plays a major role in their kits' faster growth. They may also spend more time nursing or huddling with kits; however, past research failed to find differences in the amount of time stereotypic and inactive mothers spend with their kits (Mason et al. 1995): all dams are very inactive during this period, showing negligible stereotypy and spending much of their time in the nest-box. This suggests that the explanation must be sought elsewhere, perhaps in milk quality or dams' readiness to let milk down [nest fur data suggesting that prolactin levels could differ between the two phenotypes (cf. Zarrow et al. 1961): one avenue for future research]. Whatever the mechanisms, inactive dams' pattern of smaller litters but faster kit growth and greater responsiveness to sons indicates no less investment overall, but instead the favouring of 'quality over quantity': an increased investment per kit consistent with the 'alternative strategies' hypothesis. Only post-natal investment seems to differ between active and inactive dams, because kit weight on PND 1 was not significantly different.

That inactive females' post-natal maternal investment was biased towards males was unexpected, or at least not predicted by either hypothesis. The opposite effect was previously found in this species in the kit retrieval test (Clausen et al. 2008); however, this finding was unexpected and no evolutionary expla- 
nation has yet been established. At the population level, maternal care is often biased towards males in many species, likely because of the greater variance in male reproductive success than female reproductive success, and the influence of maternal attention on this success (see Introduction). In wild mink, larger adult body sizes benefit males during competition for mates (Dunstone 1993); in farmed mink, large males also copulate for longer (Thom et al. 2004), while larger, relatively inactive males win more copulations in mate choice tests than do light bodied, highly stereotypic males (Díez-León \& Mason 2010). Because inactive dams' sons are likely to inherit low activity levels and, consequently, have heavy body weights (Mason et al. 1995; Hansen et al. 2010), they are inherently more likely to succeed with females in the mating season. It is thus unsurprising that these potentially successful breeders are favoured by their mothers. Inactive dams may therefore be boosting their sons' future success yet further, both by producing small litters, which our data show improves male kit growth particularly, and, independently, by devoting more maternal care to them. These hypothesized links between inactive dams' behaviour, their sons' growth rates during the suckling period and these males' copulatory success in adulthood, now need to be tested directly.

The evolutionary framework of the 'pace of life' idea and other adaptive explanations for behavioural syndromes underlying our 'alternative strategies' hypothesis, along with the sexual selection ideas presented above, both indicate the great potential value of applying functional, evolutionary approaches to farmed animals. However, they also raise little-explored questions about the types of selective pressures such populations are under, and the effects that captivity can have on the correlates of personality traits. Our subjects certainly showed extremes of activity likely absent in free-living wild conspecifics. This is difficult to determine definitively, because studies of wild mink activity have very small sample sizes. For example, Zschille et al. (2010) present data from four female mink with a range of $56-65 \%$ of the day spent stationary, compared to our range of $0-98 \%$ of the time inactive, but their standard error with that small sample size is still similar to that in our population. However, we estimate that our least active mink curled up in their nest-boxes for more than $23 \mathrm{~h}$ daily (cf. the $70-86 \%$ of every day spent in dens by wild conspecifics: Dunstone 1993), while at the other extreme, our most stereotypic mink paced and head-twirled abnormally for hours, and extrapolating from their average speed, some paced over $12 \mathrm{~km} / \mathrm{d}$ - further than the typical distances covered by wild mink (Gerell 1970). In general, the influences of captivity upon behaviour can occur in three main ways. One is that animals display immediate behavioural differences from wild conspecifics, caused by the constraints placed on some activities (e.g. flying, ranging widely) and the loss of need for others (e.g. food provisioning eliminates needs to forage). If captivebred, animals can also show further behavioural and physiological changes that are caused by unnatural rearing conditions (e.g. fertility problems, premature mortality and more stereotypic behaviour: Latham $\delta$ Mason 2004; Clubb et al. 2009; Jones et al. 2011). Third, altered selection pressures over multiple generations cause additional behavioural changes (e.g. Price 1999; McPhee 2004; McDougall et al. 2006). Captivity will thus often influence the range of behavioural phenotypes expressed, and potentially which traits cluster in syndromes. It may also affect the correlates of a given phenotype, for example, by altering the proximate fitness-related outcomes of behaviour by reducing risks of mortality (because animals are protected from predators) or reducing the need to search for food and thus the benefits of activity (see, for example, McPhee 2004). Although many fundamental, evolution-oriented studies of animal personality are laboratory based, some using subjects captive-bred for generations and/or small, non-enriched cages likely to induce stereotypic behaviour or extreme inactivity (e.g. Careau et al. 2008; Wilson et al. 2009), these important issues and their implications for data generality seem little acknowledged as yet in such research (Smith \& Blumstein 2008; Archard \& Braithwaite 2010 providing two welcome exceptions).

For farmed mink, we consequently cannot tell whether the observed phenomena reflect evolutionary legacies from their wild ancestors (this species only has been farmed for c.100 yrs; Hansen 1996), selective pressures acting within farms, or both. Thus, if inactive females truly have slower-paced life histories, for instance, their average lifespans should be longer (Réale et al. 2010; Table 1) - but whether this is true on farms and/or in these animals' wild forebears remains to be tested. Captive farmed mink do still face evolutionary pressures: for instance, sexual selection can occur because in the breeding season females are given opportunities to mate with multiple males, some of which they reject while others are so successful that farmers keep them for breeding an additional year; and relatively high kit mortality rates (Dunstone 1993) indicate the poten- 
tial for natural selection to improve maternal behaviour too. Studies of wild mink are therefore now necessary to determine whether the relationships observed here between behavioural phenotypes and reproductive variables resemble those in wild populations. Mink could also prove to be a good model for future research comparing the fitness correlates of personality traits in farm conditions, in the wild, and perhaps in more naturalistic forms of captive housing (e.g. large enriched enclosures).

\section{Acknowledgements}

We thank the farm owners, Kirk Rankin and Ted and Lyn Parkinson, and their staff for their help, advice and cooperation, and NSERC, the Mink Farmers Research Foundation, and the Canada Mink Breeders Association for funding. Thank you also to William Sears and Margaret Quinton for statistical advice, Allan Edelsparre, María Díez-León, Mike Walker, Carole Fureix, Cleo Beaulieu, Jamie Dallaire and Heather Kinkaid for comments on the manuscript, and Megan Jones for helpful discussion.

\section{Literature Cited}

Alvergne, A., Jokela, M. \& Lummaa, V. 2010: Personality and reproductive success in a high-fertility human population. Proc. Natl. Acad. Sci. U.S.A. 107, $11745-11750$.

Andersen, I. L., Berg, S. \& Boe, K. E. 2005: Crushing of piglets by the mother sow (Sus scrofa) - purely accidental or a poor mother? Appl. Anim. Behav. Sci. 93, $229-243$.

Anisman, H. \& Matheson, K. 2005: Stress, depression, and anhedonia: caveats concerning animal models. Neurosci. Biobehav. Rev. 29, 525-546.

Archard, G. A. \& Braithwaite, V. A. 2010: The importance of wild populations in studies of animal temperament. J. Zool. 281, 149-160.

Bahr, N. I., Pryce, C. R., Döbeli, M. \& Martin, R. D. 1998: Evidence from urinary cortisol that maternal behavior is related to stress in gorillas. Physiol. Behav. 64, 429-437.

Bakken, M. 1995: Sex-ratio variation and maternal investment in relation to social environment among farmed silver-fox vixens (Vulpes vulpes) of high competition capacity. J. Anim. Breed. Genet. 112, 463-468.

Bakken, M. 1998: The effect of an improved man-animal relationship on sex ratio in litters and on growth and behaviour in cubs among farmed silver fox (Vulpes vulpes). Appl. Anim. Behav. Sci. 56, 309-317.

Bildsøe, M., Heller, K. E. \& Jeppesen, L. L. 1990: Stereotypies in female ranch mink: seasonal and diurnal variation. Scientifur 14, 243-248.
Bildsøe, M., Heller, K. E. \& Jeppesen, L. L. 1991: Effects of immobility stress and food restriction on stereotypies in low and high stereotyping female ranch mink. Behav. Processes 25, 179-189.

Biro, P. A. \& Stamps, J. A. 2008: Are animal personality traits linked to life-history productivity? Trends Ecol. Evol. 23, 361-368.

Boon, A. K., Réale, D. \& Boutin, S. 2007: The interaction between personality, offspring fitness and food abundance in North American red squirrels. Ecol. Lett. 10, 1094-1104.

Cameron, E. Z. 2004: Facultative adjustment of mammalian sex ratios in support of the Trivers-Willard hypothesis: evidence for a mechanism. Proc. R. Soc. B 271, 1723-1728.

Careau, V., Thomas, D., Humphries, M. M. \& Réale, D. 2008: Energy metabolism and animal personality. Oikos 117, 641-653.

Careau, V., Réale, D., Humphries, M. M. \& Thomas, D. W. 2010: The pace of life under artificial selection: personality, energy expenditure, and longevity are correlated in domestic dogs. Am. Nat. 175, 753-758.

Carlstead, K. 1996: Effects of captivity on the behavior of wild mammals. In: Wild Mammals in Captivity (Kleiman, D. G., Allen, M. E., Thompson, K. V. \& Lumpkin, S., eds). Univ. of Chicago Press, Chicago, IL, pp. 317-333.

Carlstead, K., Brown, J. L. \& Seidensticker, J. 1993: Behavior and adrenocortical responses to environmental changes in leopard cats (Felis bengalensis). Zoo Biol. 12, 321-331.

Carlstead, K., Mellen, J. \& Kleiman, D. G. 1999: Black rhinoceros (Diceros bicornis) in US zoos: I. Individual behavior profiles and their relationship to breeding success. Zoo Biol. 18, 17-34.

Clausen, K. T., Malmkvist, J. \& Surlykke, A. 2008: Ultrasonic vocalisations of kits during maternal kit-retrieval in farmed mink, Mustela vison. Appl. Anim. Behav. Sci. 114, 582-592.

Clubb, R., Rowcliffe, M., Lee, P., Mar, K. U., Moss, C. $\delta$ Mason, G. J. 2009: Fecundity and population viability in female zoo elephants: problems and possible solutions. Anim. Welfare 18, 237-247.

Cronin, G. M. 1985: The development and significance of abnormal stereotyped behaviours in tethered sows, PhD Thesis. Agricultural Univ. of Wageningen, Netherlands.

Dall, S. R., Houston, A. I. \& McNamara, J. M. 2004: The behavioural ecology of personality: consistent individual differences from an adaptive perspective. Ecol. Lett. 7, 734-739.

Dallaire, J. A., Meagher, R. K., Díez-León, M., Garner, J. P. \& Mason, G. J. 2011: Recurrent perseveration correlates with abnormal repetitive locomotion in adult mink but is not reduced by environmental enrichment. Behav. Brain Res. 224, 213-222. 
Deacon, R. 2006: Assessing nest building in mice. Nat. Protoc. 1, 1117-1119.

Díez-León, M. \& Mason, G. J. 2010: Male mink (Mustela vison) from enriched cages are more successful as mates. Proc.44th Int. Congress ISAE, 96.

Dobson, J., Mason, G. \& Rouvinen-Watt, K. 2008: Intensive handling of mink (Neovison vison) dams during lactation reduces litter performance and weaning weight. Scientifur 32, 182-183.

Dunstone, N. 1993: The mink. T. \& A.D. Poyser Ltd., London.

European Commission, Scientific Committee on Animal Welfare. 2001: The welfare of animals kept for fur production. [Online] Available: http://ec.europa.eu/food/ fs/sc/scah/out67_en.pdf [7 September 2008].

Faust, L. J. \& Thompson, S. D. 2000: Birth sex ratio in captive mammals: patterns, biases, and the implications for management and conservation. Zoo Biol. 19, $11-25$.

Gerell, R. 1970: Home ranges and movements of the mink Mustela vison Shreber in Southern Sweden. Oikos 21, 160-173.

Girard, I. \& Garland, T. 2002: Plasma corticosterone response to acute and chronic voluntary exercise in female house mice. J. Appl. Physiol. 92, 1553-1561.

Gosling, S. D. 2001: From mice to men: what can we learn about personality from animal research? Psychol. Bull. 127, 45-86.

Grafen, A. \& Hails, R. 2002: Modern Statistics for the Life Sciences. Oxford Univ. Press Inc., New York, NY.

Hansen, C. P. B. 1993: Stereotypies in ranch mink - the effect of genes, litter size and neighbors. Behav. Processes 29, 165-178.

Hansen, S. W. 1996: Selection for behavioural traits in farm mink. Appl. Anim. Behav. Sci. 49, 137-148.

Hansen, S. W. \& Jeppesen, L. L. 2006: Temperament, stereotypies and anticipatory behaviour as measures of welfare in mink. Appl. Anim. Behav. Sci. 99, $172-182$.

Hansen, S. W. \& Møller, S. H. 2008: Diurnal activity patterns of farm mink (Mustela vison) subjected to different feeding routines. Appl. Anim. Behav. Sci. 111, 146-157.

Hansen, B. K., Jeppesen, L. L. \& Berg, P. 2010: Stereotypic behaviour in farm mink (Neovison vison) can be reduced by selection. J. Anim. Breed. Genet. 127, 64-73.

Harjunpaa, S. \& Rouvinen-Watt, K. 2004: The development of homeothermy in mink (Mustela vison). Comp. Biochem. Physiol. A 137, 339-348.

Hemsworth, P. H. 2003: Human-animal interactions in livestock production. Appl. Anim. Behav. Sci. 81, 185-198.

Hollander, F. A., Van Overveld, T., Tokka, I. \& Matthysen, E. 2008: Personality and nest defence in the great tit (Parus major). Ethology 114, 405-412.
Hynes, A. M., Rouvinen-Watt, K. \& Armstrong, D. 2008: Body condition and glycemic control in mink females during reproduction and lactation. Scientifur $\mathbf{2 8 ,}$ 79-86.

Janczak, A. M., Pedersen, L. J., Rydhmer, L. \& Bakken, M. 2003: Relation between early fear- and anxietyrelated behaviour and maternal ability in sows. Appl. Anim. Behav. Sci. 82, 121-135.

Jeppesen, L. L., Heller, K. E. \& Bildsøe, A. 2004: Stereotypies in female farm mink (Mustela vison) may be genetically transmitted and associated with higher fertility due to effects on body weight. Appl. Anim. Behav. Sci. 86, 137-143.

Jeschke, J. M. \& Kokko, H. 2009: The roles of body size and phylogeny in fast and slow life histories. Evol. Ecol. 23, 867-878.

Jones, M. A., Mason, G. J. \& Pillay, N. 2011: Correlates of birth origin effects on the development of stereotypic behaviour in striped mice, Rhabdomys. Anim. Behav. 82, 149-159.

King, C. M. \& Powell, R. A. 2007: The Natural History of Weasels and Stoats: Ecology, Behavior and Management. Oxford Univ. Press, Oxford, p. 148.

Kleinbaum, D. G. \& Klein, M. 2005: Survival Analysis: A Self-learning Approach, 2nd edn. Springer, New York, NY.

Koolhaas, J. M., Korte, S. M., De Boer, S. F., Van Der Vegt, B. J., Van Reenen, C. G., Hopster, H., De Jong, I. C., Ruis, M. A. W. \& Blokhuis, H. J. 1999: Coping styles in animals: current status in behavior and stress-physiology. Neurosci. Biobehav. Rev. 23, 925-935.

Korhonen, H. T., Jauhiainen, L. \& Rekila, T. 2002: Effect of temperament and behavioural reactions to the presence of a human during the pre-mating period on reproductive performance in farmed mink (Mustela vison). Can. J. Anim. Sci. 82, 275-282.

Latham, N. \& Mason, G. 2004: From house mouse to mouse house: the behavioural biology of free-living Mus musculus and its implications in the laboratory. Appl. Anim. Behav. Sci. 86, 261-289.

Malmkvist, J. \& Houbak, B. 2000: Measuring maternal care in mink: kit retrieval test. Scientifur 24, 159161.

Malmkvist, J. \& Palme, R. 2008: Periparturient nest building: implications for parturition, kit survival, maternal stress and behaviour in farmed mink (Mustela vison). Appl. Anim. Behav. Sci. 114, 270-283.

Marai, F. M. \& Rashwan, A. A. 2003: Rabbits behaviour under modern commercial production conditions - a review. Arch. Tierz. 46, 357-376.

Mason, G. J. 1992: Individual variation in the stereotypies of caged mink. PhD Thesis. Univ. of Cambridge, UK.

Mason, G. J. 1993: Age and context affect the stereotypies of caged mink. Behaviour 127, 191-229. 
Mason, G. J. 1994: The influence of weight, sex, birth date and maternal age on the growth of weanling mink. J. Zool. 233, 203-214.

Mason, G. J. \& Latham, N. R. 2004: Can't stop, won't stop: is stereotypy a reliable animal welfare indicator? Anim. Welfare 13, 57-69.

Mason, G. J., Leipoldt, A. \& de Jonge, G. 1995: Why do female mink with high stereotypy levels have slowgrowing offspring? Proc. 29th Int. Congress ISAE, 133-134.

McDougall, P. T., Réale, D., Sol, D. \& Reader, S. M. 2006: Wildlife conservation and animal temperament: causes and consequences of evolutionary change for captive, reintroduced, and wild populations. Anim. Conserv. 9, 39-48.

McPhee, M. E. 2004: Generations in captivity increases behavioral variance: considerations for captive breeding and reintroduction programs. Biol. Conserv. 115, $71-77$.

Meagher, R. \& Mason, G. 2008: The relationship between inactivity, reproductive performance and welfare state in mink. Proc. 42nd Int. Congress ISAE, 7.

Meagher, R., Hunter, B., Bechard, A. \& Mason, G. 2010: When inactivity predicts poor reproductive success in farmed mink, is poor welfare the link? Proc.44th Int. Congress ISAE, 55.

Meagher, R. K., Duncan, I., Bechard, A. \& Mason, G. J. 2011: Who's afraid of the big bad glove? Testing for fear and its correlates in mink. Appl. Anim. Behav. Sci. 133, 254-264.

Meagher, R. K., Bechard, A., Palme, R., Díez-León, M., Hunter, D. B. \& Mason, G. J. (in press): Decreased litter size in inactive female mink (Neovison vison): mechanisms and implications for overall productivity. Can. J. Anim. Sci. in press.

Møller, S. 1990: The need for nest-boxes and drop-in bottoms in the whelping period of female mink. Scientifur 14, 95-100.

Pedersen, L. J., Jorgensen, E., Heiskanen, T. \& Damm, B. I. 2006: Early piglet mortality in loose-housed sows related to sow and piglet behaviour and to the progress of parturition. Appl. Anim. Behav. Sci. 96, 215-232.

Price, E. O. 1999: Behavioral development in animals undergoing domestication. Appl. Anim. Behav. Sci. 65, 245-271.

Réale, D., Reader, S. M., Sol, D., McDougall, P. T. \& Dingemanse, N. J. 2007: Integrating animal temperament within ecology and evolution. Biol. Rev. 82, 291-318.

Réale, D., Dingemanse, N. J., Kazem, A. J. N. \& Wright, J. 2010: Evolutionary and ecological approaches to the study of personality. Philos. Trans. R. Soc. Lond. B Biol. Sci. 365, 3937-3946.

Roberts, M. F. 1977: All About Ferrets. T.F.H. Publications Inc. Ltd., Neptune City, New Jersey.
Rochlitz, I., Podberscek, A. L. \& Broom, D. M. 1998: Welfare of cats in a quarantine cattery. Vet. Rec. 143, 35-39.

Searle, S. R., Casella, G. \& McCulloch, C. E. 1992: Variance Components. Wiley Interscience, New York, NY.

Sih, A., Bell, A. \& Johnson, J. C. 2004: Behavioral syndromes: an ecological and evolutionary overview. Trends Ecol. Evol. 19, 372-378.

Sikes, R. S. \& Ylönen, H. 1998: Considerations of optimal litter size in mammals. Oikos 83, 452-465.

Smith, B. R. \& Blumstein, D. T. 2008: Fitness consequences of personality: a meta-analysis. Behav. Ecol. 19, 448-455.

Stewart, R. C. 2007: Maternal depression and infant growth - a review of recent evidence. Matern. Child Nutr. 3, 94-107.

Svendsen, P. M., Hansen, B. K., Malmkvist, J., Hansen, S. W., Palme, R. \& Jeppesen, L. L. 2007a: Selection against stereotypic behaviour may have contradictory consequences for the welfare of farm mink (Mustela vison). Appl. Anim. Behav. Sci. 107, 110-119.

Svendsen, P. M., Hansen, S. W. \& Jeppesen, L. L. 2007b: Direct scan sampling reliably reflects video recorded differences in stereotypy in selected lines of mink. Scientifur 31, 19-25.

Thom, M. D., Macdonald, D. W., Mason, G. J., Pedersen, V. \& Johnson, P. J. 2004: Female American mink, Mustela vison, mate multiply in a free-choice environment. Anim. Behav. 67, 975-984.

Trivers, R. L. \& Willard, D. E. 1973: Natural-selection of parental ability to vary sex-ratio of offspring. Science 179, 90-92.

Verbeek, M. E., Drent, P. J. \& Wiepkema, P. R. 1994: Consistent individual differences in early exploratory behaviour of male great tits. Anim. Behav. 48, 1113-1121.

Wells, J. C. K. 2003: Parent-offspring conflict theory, signaling of need, and weight gain in early life. Q. Rev. Biol. 78, 169-202.

Wemelsfelder, F., Nevison, I. \& Lawrence, A. B. 2009: The effect of perceived environmental background on qualitative assessments of pig behaviour. Anim. Behav. 78, 477-484.

Wielebnowski, N. C., Fletchall, N., Carlstead, K., Busso, J. M. \& Brown, J. L. 2002: Noninvasive assessment of adrenal activity associated with husbandry and behavioral factors in the North American clouded leopard population. Zoo Biol. 21, 77-98.

Willner, P. 1997: Validity, reliability and utility of the chronic mild stress model of depression: a 10-year review and evaluation. Psychopharmacology 134, 319-329.

Wilson, A. J., Gelin, U., Perron, M. C. \& Réale, D. 2009: Indirect genetic effects and the evolution of aggression in a vertebrate system. Proc. R. Soc. B 276, 533-541. 
Wingfield, J. C. \& Sapolsky, R. M. 2003: Reproduction and resistance to stress: when and how. J. Neuroendocrinol. 15, 711-724.

Wolf, M., van Doorn, G. S., Leimar, O. \& Weissing, F. J. 2007: Life-history trade-offs favour the evolution of animal personalities. Nature 447, 581-584.

Zarrow, M. X., Sawin, P. B., Ross, S., Denenberg, V. H., Crary, D., Wilson, E. D. \& Farooq, A. 1961: Maternal behaviour in the rabbit: evidence for an endocrine basis of maternal-nest-building and additional data on maternal-nest-building in the Dutch-belted race. J. Reprod. Fertil. 2, 152-162.

Zeller, A. C. 1991: Human response to primate deviance. Anthropologica 33, 39-68.

Zschille, J., Stier, N. \& Roth, M. 2010: Gender differences in activity patterns of American mink Neovison vison in Germany. Eur. J. Wildl. Res. 56, 187-194. 